\title{
Chemical synthesis of monodisperse $\gamma$-Fe-Ni magnetic nanoparticles with tunable Curie temperatures for self-regulated hyperthermia
}

\author{
K. L. McNerny, ${ }^{1, a)}$ Y. Kim, ${ }^{1}$ D. E. Laughlin, ${ }^{1}$ and M. E. McHenry ${ }^{1,2}$ \\ ${ }^{1}$ Department of Materials Science and Engineering, Carnegie Mellon University, Pittsburgh, Pennsylvania \\ 15213, USA \\ ${ }^{2}$ Deparment of Biomedical Engineering, Carnegie Mellon University, Pittsburgh, Pennsylvania 15213, USA
}

(Presented 22 January 2010; received 31 October 2009; accepted 17 December 2009; published online 19 April 2010)

\begin{abstract}
Magnetic nanoparticles (MNPs) possessing low Curie temperatures ( $\mathrm{T}_{\mathrm{C}}$ 's) offer the possibility for self-regulated heating of cancer cells, where the $\mathrm{T}_{\mathrm{C}}$ acts as an upper limit to heating to prevent damage to neighboring healthy tissue. We report the synthesis of monodisperse metastable fcc $\gamma$-phase $\mathrm{Fe}-\mathrm{Ni}$ MNPs possessing tunable $\mathrm{T}_{\mathrm{C}}$ 's, whose stoichiometries have been predicted from metastable extensions to an equilibrium $\mathrm{Fe}-\mathrm{Ni}$ phase diagram. Metastable alloys have been predicted within the constructs of the $\mathrm{T}_{0}$ construction in the $\mathrm{Fe}-\mathrm{Ni}$ eutectoid phase diagram. $\mathrm{Fe}-\mathrm{Ni}$ MNPs have been synthesized via chemical reduction in Fe- and Ni-precursors with stoichiometries ranging from $\mathrm{Fe}_{90} \mathrm{Ni}_{10}$ to $\mathrm{Fe}_{70} \mathrm{Ni}_{30}$. Mn-precursors have been added to further reduce the alloy's $\mathrm{T}_{\mathrm{C}}$. MNP morphology and structure have been confirmed by $\mathrm{x}$-ray diffraction and transmission electron microscopy while magnetic properties were investigated using vibrating sample magnetometry. $\mathrm{Fe}_{70} \mathrm{Ni}_{30}$ MNPs were found to have a $\mathrm{T}_{\mathrm{C}}$ of $82{ }^{\circ} \mathrm{C}$ and specific magnetization of $66 \mathrm{emu} / \mathrm{g}$. Addition of 1 wt $\% \mathrm{Mn}$ to $\mathrm{Fe}_{75} \mathrm{Ni}_{25}$ reduced the $\mathrm{T}_{\mathrm{C}}$ to $78{ }^{\circ} \mathrm{C}$, which is the lowest reported for fcc $\mathrm{Fe}-\mathrm{Ni}$ alloys. We also report a model for radio frequency self-regulated heating, in which the maximum achievable temperature of water-MNP suspensions $\left(\mathrm{T}_{\mathrm{C}}<100{ }^{\circ} \mathrm{C}\right)$ or octyl ether-MNP suspensions $\left(\mathrm{T}_{\mathrm{C}}>100{ }^{\circ} \mathrm{C}\right)$ is approximately the $\mathrm{T}_{\mathrm{C}}$ of the MNPs suspended in the solution. (C) 2010 American Institute of Physics. [doi:10.1063/1.3348738]
\end{abstract}

\section{INTRODUCTION}

Magnetic properties of 3d-transition metal alloys have been extensively studied for the last 70 years; however, little is known about the metastable extension of the fcc gammaphase in the iron-rich region of the iron-nickel $(\mathrm{FeNi})$ phase diagram at low temperatures. By extending the known compositional dependence of Curie temperature $\left(\mathrm{T}_{\mathrm{C}}\right)$ for the fcc $\gamma$-phase at high $\mathrm{Ni}$ concentrations, we expect metastable $\gamma$-FeNi alloys to have low $\mathrm{T}_{\mathrm{C}}$ 's in the Fe-rich region of the phase diagram, making it suitable for self-regulated radio frequency (rf) heating in cancer hyperthermia. Hyperthermia, a mode of cancer treatment referring to the heating of tumor regions to $42-46{ }^{\circ} \mathrm{C}$ for an extended period of time, has been explored as a means to enhance the effects of conventional chemotherapeutic agents and radiation. It is wellknown that the vascular system is poorly developed in cancerous tissue and has a lower thermal resistance than healthy tissue; therefore magnetic nanoparticles (MNPs) have been examined as point sources for localized heating of cancer tissue, to minimize the effects on healthy tissue. ${ }^{1,2}$

Under a nonbioinvasive rf magnetic field, MNPs in ferrofluids dissipate heat via Néel and Brownian relaxation losses. ${ }^{3}$ Losses are diminished at the $\mathrm{T}_{\mathrm{C}}$ of a ferromagnetic material providing an upper limit to the maximum temperature achieved through heating. ${ }^{4}$ If the $\mathrm{T}_{\mathrm{C}}$ is brought near the desired maximum temperature, the heating can be selfregulating and thus minimally invasive. In prior work, ${ }^{3}$ it has

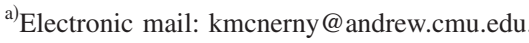

been shown that the largest heating rate in ferrofluids is achievable for metallic nanoparticles having the largest saturation inductions suggesting FeCo MNPs for use in hyperthermic heating. ${ }^{5} \mathrm{FeCo}$, however, has a large Curie temperature. To exploit self-regulated heating in materials with $\mathrm{T}_{\mathrm{C}}$ 's near hyperthermic temperatures, other alloys must be explored.

Some research has shown that low $\mathrm{T}_{\mathrm{C}}$ 's are achievable for Fe-rich compositions of fcc $\gamma$-FeNi alloys at low temperatures. ${ }^{6}$ Because this phase is metastable at low temperatures in this region of the phase diagram, we have annealed samples to $800{ }^{\circ} \mathrm{C}$ and rapidly quenched in order to stabilize the $\gamma$-phase. We report the synthesis of phase pure fcc $\gamma$-FeNi with compositions ranging from $\mathrm{Fe}_{90} \mathrm{Ni}_{10}$ to $\mathrm{Fe}_{70} \mathrm{Ni}_{30}$ as well as the reduction in $\mathrm{T}_{\mathrm{C}}$ by varying stoichiometries.

\section{EXPERIMENTAL PROCEDURE}

$\mathrm{Fe}_{\mathrm{x}} \mathrm{Ni}_{1-\mathrm{x}}$ nanoparticles were prepared by chemical reduction in iron (III) acetylacetonate and nickel (II) acetylacetonate by 1,2-hexadecanediol in the presence of oleic acid and oleylamine (all chemicals were purchased from SigmaAldrich). In a typical procedure, molar ratios of iron (III) acetylacetonate and nickel (II) acetylacetonate were added to a $100 \mathrm{ml}$ three-neck round bottom flask with a mechanical stirrer and mixed with $25 \mathrm{ml}$ dioctyl ether. After purging with high-purity argon for $20 \mathrm{~min}$ at room temperature, the flask was heated to $130{ }^{\circ} \mathrm{C}$ for $15 \mathrm{~min}$ and then heated to $285{ }^{\circ} \mathrm{C}$ for $30 \mathrm{~min}$ followed by cooling. The black product was pre- 

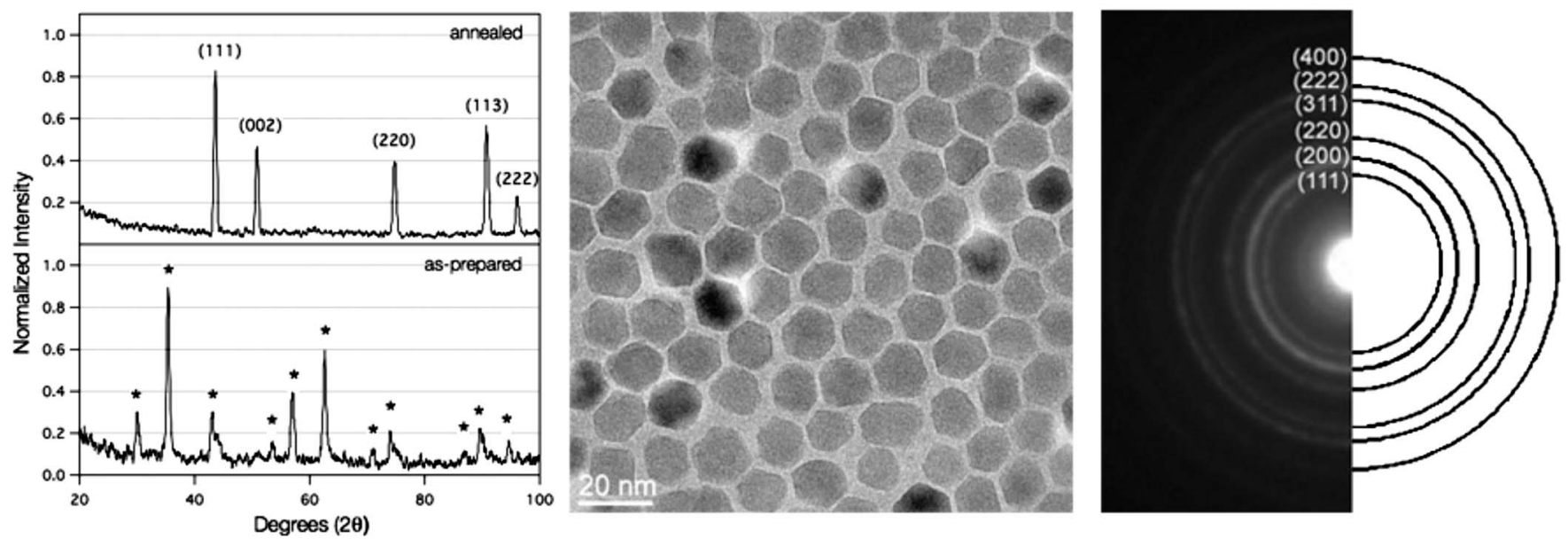

FIG. 1. (a) XRD patterns of as-prepared FeNi nanoparticles with substantial oxidation (bottom) and annealed $\mathrm{Fe}_{80} \mathrm{Ni}_{20}$ nanoparticles (top) (labeled peaks correspond to fcc $\gamma-\mathrm{Fe}_{80} \mathrm{Ni}_{20}$ and asterisks correspond to $\left.(\mathrm{Fe}, \mathrm{Ni})_{3} \mathrm{O}_{4}\right)$; (b) TEM images of monodisperse as-prepared FeNi nanoparticles; and (c) corresponding SAED pattern (rings are indexed to gamma-FeNi).

cipitated by addition of ethanol followed by centrifugation. Mn-containing $\mathrm{Fe}_{\mathrm{x}} \mathrm{Ni}_{1-\mathrm{x}}$ nanoparticles were prepared via the same technique while also adding Mn (III) acetylacetonate to the starting materials.

To reduce the oxide shell that forms during synthesis, nanoparticle powder and tantalum turnings, which act as an oxygen-getter, were sealed under vacuum of $\sim 175$ torr in a quartz tube. The tube was heated to $800{ }^{\circ} \mathrm{C}$ in $1 \mathrm{~h}$, maintained at $800{ }^{\circ} \mathrm{C}$ for $1 \mathrm{~h}$, and quenched in a cold-water bath.

Powder x-ray diffraction (XRD) was collected using a Rigaku powder diffractometer. Data was collected from $20^{\circ}$ to $100^{\circ} 2 \theta$ in $0.05^{\circ}$ steps with a scan rate of $1.5^{\circ} / \mathrm{min}$. The instrument was operated at $35 \mathrm{kV}$ and $25 \mathrm{~mA}$ using monochromatic $\mathrm{Cu} K \alpha$ radiation. A rough mean particle size was determined from broadening of the (111) peak by using Scherrer's equation.

Particle size evaluation and structural characterization were performed using a JEOL 2000EX transmission electron microscope (TEM). Selected area diffraction (SAED) was used to identify crystalline phases in the nanoparticles and confirm the presence of the fcc $\gamma$-phase. Samples for TEM analysis were prepared by passing a carbon coated $\mathrm{Cu}$ TEM grid through a monolayer of hexane dispersed nanoparticles floated over ethanol. Grids were allowed to dry in air at room temperature.

Magnetic measurements were obtained using a Lakeshore vibrating sample magnetometer equipped with a furnace that can operate to $1300 \mathrm{~K}$. M versus T measurements were performed in an external field of 500 Oe. For heating experiments, $\mathrm{Fe}-\mathrm{Ni}$ MNPs were suspended in dioctyl ether for MNPs having $\mathrm{T}_{\mathrm{C}}>100{ }^{\circ} \mathrm{C}$ and in water for $\mathrm{T}_{\mathrm{C}}$ $<100{ }^{\circ} \mathrm{C}$. MNP suspensions were placed in the center of a rf coil and exposed to an alternating magnetic field of $\mathrm{H}$ $=540$ Oe and $\mathrm{f}=280 \mathrm{kHz}$, which is less than the maximum combination of field and frequency for nonbioinvasive applications $\left(\mathrm{H}^{*} \mathrm{f} \leq 6.1 \times 10^{6} \mathrm{Oe} / \mathrm{s}\right){ }^{7}$

\section{RESULTS AND DISCUSSION}

XRD patterns for synthesized MNPs before and after annealing are shown in Fig. 1(a). X-ray analysis reveals that the as-prepared MNPs are predominantly the spinel ferrite, $(\mathrm{Fe}, \mathrm{Ni})_{3} \mathrm{O}_{4}$. After annealing, however, it is evident that the oxide has been reduced by the oxygen-getter, and the fcc $\gamma$-phase is formed. Lattice parameter calculations reveal that as iron-content increases, the unit cell size increases (Table I).

Power loss has been shown to be dependent upon particle size, and optimal power losses are only achieved in a narrow range of particle sizes, though this is predicted to be less important for self-regulated heating. ${ }^{3} \mathrm{X}$-ray analysis confirms particle coarsening as annealing time was increased. Control over annealing time was used to achieve optimal particle sizes that are expected to yield the largest volumetric power loss. A volumetric power loss of 2 $\times 10^{9} \mathrm{~W} / \mathrm{m}^{3}$ can be estimated for $\gamma$-FeNi MNPs with a mean particle size of about $46 \mathrm{~nm}$. Magnetic parameters $\left(\mathrm{M}_{\mathrm{d}}=727 \mathrm{kA} / \mathrm{m}\right.$ and $\left.\mathrm{K}=600 \mathrm{~J} / \mathrm{m}^{3}\right)$ used to calculate volumetric power losses for varying particle sizes were taken from Refs. 8 and 9, respectively.

Figure 1(b) shows a typical TEM image of monodisperse as-prepared $\mathrm{FeNi} /(\mathrm{Fe}, \mathrm{Ni})_{3} \mathrm{O}_{4}$ nanoparticles with either a spherical or faceted morphology. Nanoparticles are monodisperse with a mean size distribution of $12.2 \mathrm{~nm}$ and standard deviation of $0.73 \mathrm{~nm}$. SAED was used to confirm the gamma-phase in as-prepared nanoparticles, as shown in Fig. 1(c). Annealing results in coarsened nanoparticles having a thin adherent $(\mathrm{Fe}, \mathrm{Ni})_{3} \mathrm{O}_{4}$ oxide shell with an average thickness of about $2 \mathrm{~nm}$. The mean particle size observed from TEM is smaller than that calculated using Scherrer's equa-

TABLE I. Dependence of alloy composition on lattice parameter.

\begin{tabular}{cc}
\hline \hline & $\begin{array}{c}\text { Lattice parameter } \\
(\AA)\end{array}$ \\
\hline Alloy composition (Fe:Ni) & 3.5895 \\
$85: 25$ & 3.5948 \\
$85: 15$ & 3.5987 \\
$86: 14$ & 3.6023 \\
$88: 12$ & 3.6043 \\
\hline
\end{tabular}



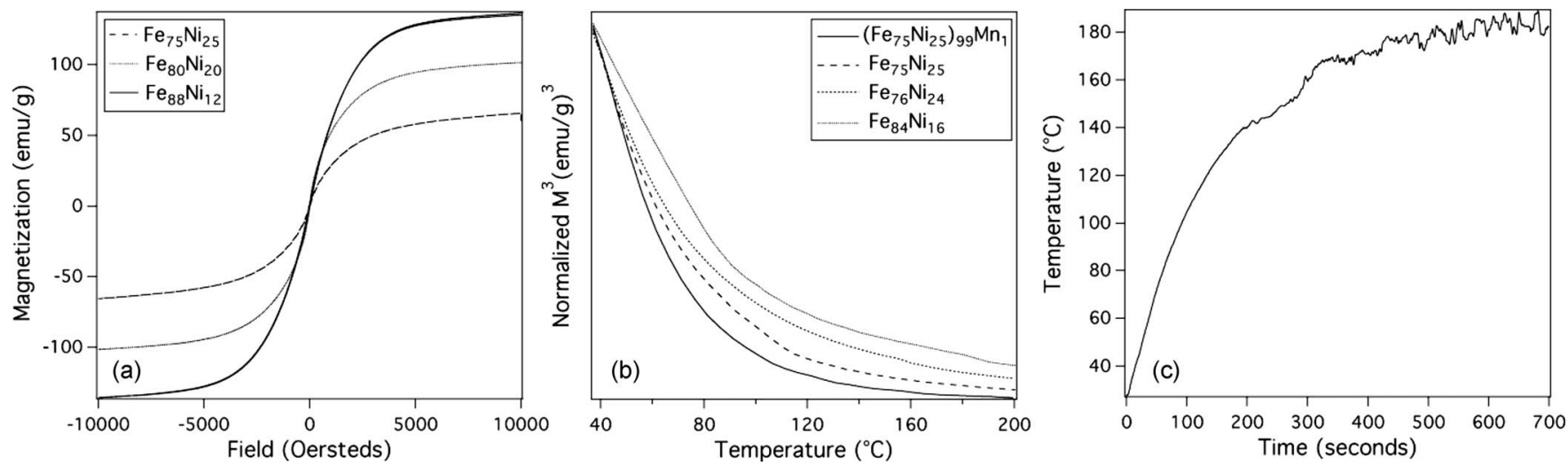

FIG. 2. (a) Hysteresis loop for annealed $\mathrm{Fe}_{1-x} \mathrm{Ni}_{\mathrm{x}}$ MNPs measured at room temperature; (b) magnetization of $\mathrm{Fe}_{1-\mathrm{x}} \mathrm{Ni}_{\mathrm{x}} \mathrm{MNPs}$ as a function of temperature in an external magnetic field of 500 Oe.; and (c) heating profile for Fe-Ni MNPs suspended in a high boiling point organic solvent when exposed to rf magnetic field.

tion from the XRD data. ${ }^{10}$ This is consistent with previous comparisons of particle sizes inferred from different structural probes. ${ }^{11}$

Hysteresis loops measured at room temperature from -10 to 10 kOe are shown in Fig. 2(a) for varying compositions. The specific magnetization was shown to increase with increasing $\mathrm{Fe}$-content from $80 \mathrm{emu} / \mathrm{g}$ for $\mathrm{Fe}_{70} \mathrm{Ni}_{30}$ to 100 emu/g for $\mathrm{Fe}_{80} \mathrm{Ni}_{20}$ to $117 \mathrm{emu} / \mathrm{g}$ for $\mathrm{Fe}_{88} \mathrm{Ni}_{12}$. This is expected as $\mathrm{Fe}$ has a larger atomic magnetic dipole moment than $\mathrm{Ni}$.

The spontaneous magnetization was measured as a function of temperature, as shown in Fig. 2(b). The Curie temperature $T_{C}$ was determined by extrapolating $\mathrm{M}^{3}$ to zero when $\mathrm{M}^{3}$ is plotted with respect to temperature. ${ }^{12}$ The spontaneous magnetization $M$ is often observed to scale as $\left(\mathrm{T}_{\mathrm{C}}-\mathrm{T}\right)^{\beta}$ with a critical exponent, $\beta=1 / 3 .^{12}$ The $\mathrm{T}_{\mathrm{C}}$ was measured to be $112{ }^{\circ} \mathrm{C}$ for nominal $\mathrm{Fe}_{84} \mathrm{Ni}_{16}$ and $82{ }^{\circ} \mathrm{C}$ for nominal $\mathrm{Fe}_{75} \mathrm{Ni}_{25}$. Mn was added to further reduce the $\mathrm{T}_{\mathrm{C}}$ of $\mathrm{Fe}-\mathrm{Ni}$ nanoparticles. The $\mathrm{T}_{\mathrm{C}}$ for $\mathrm{Mn}$-containing $\mathrm{Fe}_{75} \mathrm{Ni}_{25}$ nanoparticles was measured to be $78{ }^{\circ} \mathrm{C}$ for our nominal $\left(\mathrm{Fe}_{75} \mathrm{Ni}_{25}\right)_{99} \mathrm{Mn}_{1}$.

There is some uncertainty in the composition of asprepared nanoparticles due to the presence of an Fe-rich oxide layer. Iron tends to oxidize more rapidly than nickel, and therefore the oxide will tend to be more Fe-rich, leaving the stoichiometry of the metal core to be more Ni-rich than stoichiometries of initial metal-precursors.

An example of a heating profile for Mn-containing $\mathrm{Fe}-\mathrm{Ni}$ nanoparticles is shown in Fig. 2(c). Nanoparticle suspensions heat until the solution exceeds the $T_{C}$ at which point heating slows and is self-regulated just above of the
$\mathrm{T}_{\mathrm{C}}$. An oscillating behavior can be seen in the heating profile as this temperature is reached, where the nanoparticles switch from ferromagnetic to paramagnetic and back to ferromagnetic as the solution temperature heats above and then cools below the $\mathrm{T}_{\mathrm{C}}$.

\section{ACKNOWLEDGMENTS}

K.L.M., M.E.M., and D.E.L. acknowledge support of the NSF through Grant No. DMR 0804020 and the Data Storage Systems Center. Y.K. gratefully acknowledges Intel First Year Research Experience (IFYRE) program for funding.

${ }^{1}$ I. Hilger, E. Dietmar, W. Lin, S. Streck, and W. A. Kaiser, J. Phys.: Condens. Matter 18, S2951 (2006).

${ }^{2}$ A. Ito, M. Shinikai, H. Honda, and T. Kobayashi, J. Biosci. Bioeng. 100, 1 (2005).

${ }^{3}$ A. H. Habib, C. L. Ondeck, P. Chaudhary, M. R. Bockstaller, and M. E. McHenry, J Appl. Phys. 103, 07A307 (2008).

${ }^{4}$ C. L. Ondeck, A. H. Habib, C. A. Sawyer, P. Ohodnicki, K. J. Miller, P. Chaudhary, and M. E. McHenry, J. Appl. Phys. 105, $07 B 324$ (2009).

${ }^{5}$ K. Gallagher, F. Johnson, E. Kirkpatrick, J. H. Scott, S. Majetich, and M. E. McHenry, IEEE Trans. Magn. 32, 4842 (1996).

${ }^{6}$ K. B. Reuter, D. B. Williams, and J. I. Goldstein, Metall. Trans. A 20, 719 (1989).

${ }^{7}$ W. J. Atkinson, I. A. Brezovich, and D. P. Chakraborty, IEEE Trans. Biomed. Eng. BME-31, 70 (1984).

${ }^{8}$ Y. Hong, Y. Rheem, M. Lain, D. M. Cwiertny, S. L. Walker, and N. V. Myung, "Electrochemical synthesis of $\mathrm{Fe}_{x} \mathrm{Ni}_{1-x}$ nanostructures for environmental remediation," Chem. Eng. J. (in press).

${ }^{9}$ F. Pfeifer and C. Radeloff, J. Magn. Magn. Mater. 19, 190 (1980).

${ }^{10}$ M. DeGraef and M. E. McHenry, Structure of Materials (Cambridge University Press, New York, 2007).

${ }^{11}$ M. A. Willard, L. K. Kurihara, E. E. Carpenter, S. Calvin, and V. G. Harris, Int. Mater. Rev. 49, 125 (2004).

${ }^{12}$ A. Belayachi, J. L. Dormann, and M. Nogues, J. Phys.: Condens. Matter 10, 1599 (1998) 